Linares, L. Modelo para armar. Familia y roles de género a través del discurso eugénico en Argentina. 1934-1945

Derecho y Ciencias Sociales. Octubre 2018. № 19. (Las familias y el derecho de las familias a dos años de vigencia del Código Civil y Comercial) Pgs 4-21. ISNN 1852-2971. Instituto de Cultura Jurídica y Maestría en Sociología Jurídica. FCJ y S. UNLP

\title{
Modelo para armar. Familia y roles de género a través del discurso eugénico en Argentina. 1934-1945
}

Family and gender roles throughout eugenic speech in Argentina between 1934-1945

\section{Luciana Linares ${ }^{\bullet}$}

\section{Resumen:}

El presente artículo pretende dar cuenta de los mecanismos de construcción de discurso utilizados por representantes de la teoría eugenésica en Argentina durante la primera mitad del siglo XX. Para ello, se recorren los dispositivos culturales de alcance popular, que principalmente médicos y profesionales de la salud, difundían con el objetivo de propagar un modelo de familia que diera respuesta a las cuestiones poblacionales del país desde el esquema de ideas eugenésicas. Así, se busca avanzar en las estrategias de legitimación del ideario que estaba presente en algunos medios de comunicación especializados y populares sobre la mujer y la familia eugénica en Argentina. De esta manera, podremos visualizar las tácticas comunicacionales utilizadas a la hora de legitimar un modelo de familia basado en la impronta de la ciencia del "buen nacer".

Palabras clave: Eugenesia; familia; mujer; medios de comunicación

\begin{abstract}
:
This article intends to account speech-construction mechanisms used by representatives of the eugenic theory in Argentina thorughout the first half of the twentieth century. For that purpose, we will to over cultural devices with popular reach that mainly doctors and healthcare professionals helped disseminate in order to spread a model of family which responded to population issues in the country bases on eugenic ideas. Therefore, we will continúe analyzing the legitimation strategies present in the ideology of popular media specialyzed in women and eugenic family in Argentina. This aporoach will allow us to visualyze communication tactics that were used to legitimate a model of family based on the imprint of the science of good birth
\end{abstract}

Keywords: Eugenics; family, woman, mass media

\footnotetext{
- Luciana Linares. Doctora, Magíster y Profesora en Historia por la Universidad Nacional de Mar del Plata. Becaria posdoctoral de CONICET, docente de dicha casa de altos estudios, especialista en estudios sobre el cuerpo, de género y medios de comunicación en Argentina. Su dirección de contacto es lucianamlinares@gmail.com.
}

Recibido: 8 /4/ 2018- Aceptado con correcciones: 3/9/2018 
Linares, L. Modelo para armar. Familia y roles de género a través del discurso eugénico en Argentina. 1934-1945 Derecho y Ciencias Sociales. Octubre 2018. № 19. (Las familias y el derecho de las familias a dos años de vigencia del Código Civil y Comercial) Pgs 4-21. ISNN 1852-2971. Instituto de Cultura Jurídica y Maestría en Sociología Jurídica. FCJ y S. UNLP

Modelo para armar. Familia y roles de género a través del discurso eugénico en Argentina. 1934-1945.

Luciana Linares

\section{Introducción}

El debate acerca de las configuraciones sociales sobre la familia es amplio y actualmente abordado desde diversos campos. Los estudios sobre la modernidad de la familia se han ido complejizando desde los aportes de PARSONS y BALES (1955) vinculados a la industrialización hasta aportes que relacionan la estructura familiar a otro tipo de lazos de carácter afectivo, como lo estudió ARIÉS (1960). De allí en más, distintos teóricos fueron pensando la familia ampliando esa mirada sobre lo cultural y lo afectivo, hasta que a mediados de 1980 algunas investigaciones se acercaron más a un análisis microsocial (SEGALEN, 2013) allí se produjo el giro desde el estudio de los grupos sociales al individuo. Con ello, la aplicación de nuevos métodos que vinculan la vida privada y lo doméstico en el análisis de los modelos familiares.

Así sabemos que los modos de socialización de los individuos responden a diferentes lógicas y van configurando pluralidades. Diversos modos de sancionar valores de familia, relaciones sociales, identidades individuales son propuestos, tomados, repensados, desarmados por las personas a la hora de establecer familias. En este sentido, el aporte de este artículo radica en dar cuenta de uno de los mecanismos utilizados para legitimar un orden de modelo de familia ideado desde la ciencia para dar respuesta a una estructura poblacional cambiante. No podemos pensarlo aquí en términos de grado de impacto dado el recorte ni abarcar históricamente el período, sino más bien hacer foco en una de estrategia de legitimación de un modelo de familia, empleada por un grupo de profesionales de la salud.

El cuerpo de fuentes a las que se refiere este trabajo radica en tres colecciones. Éstas fueron seleccionadas a partir de los siguientes criterios: revistas de divulgación popular orientadas a temáticas de salud y familia, vigentes entre mediados de la década de 1930 hasta 1955. El recorte temporal fue resultado, por un lado la proliferación de medios de comunicación especializados en salud y orientados a difundir pautas cotidianas y familiares de comportamiento y por otro responde a la necesidad de analizar los mecanismos de divulgación y construcción de legitimidad de los discursos eugénicas en Argentina hasta 
Linares, L. Modelo para armar. Familia y roles de género a través del discurso eugénico en Argentina. 1934-1945 Derecho y Ciencias Sociales. Octubre 2018. № 19. (Las familias y el derecho de las familias a dos años de vigencia del Código Civil y Comercial) Pgs 4-21. ISNN 1852-2971. Instituto de Cultura Jurídica y Maestría en Sociología Jurídica. FCJ y S. UNLP

mediados de la década de 1950. Las tres colecciones referidas pertenecen a las revistas Viva Cien Años (VCA), Hijo Mío! Y Nuestros Hijos.

Entonces este artículo presentará algunos de los mecanismos de construcción de discurso utilizados por representantes de la corriente eugenésica ${ }^{1}$ en Argentina durante la primera mitad del siglo XX. Para ello, se recorren los dispositivos culturales de alcance popular, que principalmente médicos y profesionales de la salud, difundían con el objetivo de propagar un modelo de familia que diera respuesta a las cuestiones poblacionales del país desde el esquema de ideas eugenésicas.

Los imaginarios sobre las familias posibles, fueron cambiando contextualizados en las transformaciones sociales, económicas, religiosas y culturales de las sociedades capitalistas occidentales $^{2}$. Estos imaginarios o ideas imperantes a la hora de normativizar el concepto de familia y todo lo que incluye/excluye este modelo, fueron en la contemporaneidad, ganando terreno en la opinión pública. Es esta quién legitima las formas y los modelos desde los cuales marcar o no pertenencias. Si bien, hoy resulta evidente leerlo en esa clave, donde las teorías comunicacionales se vuelven a plantear el lugar del género (LOVERA, 2009) los modelos de familia, los roles de género y el deber ser de los cuerpos, tiene un largo recorrido en los medios de comunicación argentinos ${ }^{3}$.

En la historia argentina, los modelos de familia fueron configurándose bajo lógicas que respondieron a diversos momentos políticos, sociales, culturales y económicos donde imperaba un discurso acerca del "deber ser" de los cuerpos. Sobre todo, de la función social de los cuerpos femeninos.

Los discursos normalizadores respecto a la familia provinieron de actores socialmente legitimados, conforme a su rol en la estructura social. Durante la primera mitad del siglo XX, la Iglesia Católica fue una de esas instituciones que educaba tanto a mujeres como varones, dentro de los cánones del modelo de familia troncal, heteronormativa. Cambios en la legislación, en los usos, el ingreso de la mujer al mercado de trabajo, el aumento en la edad de

\footnotetext{
${ }^{1}$ Por teoría eugenésica entendemos los postulados de GALTON, quien acuño el termino eugenesia para definir una disciplina de conocimiento científico que postula el mejoramiento racial y el "buen nacer" como eje de los programas poblacionales. Emergente hacia finales del siglo XIX en Inglaterra

${ }^{2}$ Sobre este punto, es interesante el planteo que realiza SEGALEN (2013) sobre estas transformaciones en torno a las familias y las sociedades enmarcadas en la cultura capitalista occidental y la íntima e incuestionable relación entre los cambios acontecidos en unas y otras. Para ello, consultar SEGALEN, (2013)

${ }^{3}$ En el marco de los estudios sobre eugenesia en Argentina en relación a los modelos de familias y roles de género en los medios de comunicación para la década de 1930 y 1940, podemos mencionar el trabajo de VEZZETTI (1985), MIRANDA (2011), LINARES (2014).
} 
Linares, L. Modelo para armar. Familia y roles de género a través del discurso eugénico en Argentina. 1934-1945 Derecho y Ciencias Sociales. Octubre 2018. № 19. (Las familias y el derecho de las familias a dos años de vigencia del Código Civil y Comercial) Pgs 4-21. ISNN 1852-2971. Instituto de Cultura Jurídica y Maestría en Sociología Jurídica. FCJ y S. UNLP

los varones y mujeres que contraen nupcias, fueron modificando estructuras parentales al grado de crear nuevos modelos de familias. Así como marcamos estos cambios en la primera mitad del siglo XX, más aún lo podemos referir para la segunda parte de la centuria.

Los medios de comunicación y el mercado del consumo, establecieron claramente una postura respecto a los modelos de familia (PÉREZ, y RIBEIRO DOS SANTOS, 2017) y las necesidades de los mismos. Así, editoriales gráficas, radios y revistas legitimaron ciertos discursos respecto a los roles de varones y mujeres dentro de la estructura social y familiar. Este proceso que se abrió hacia 1930, continuo durante todo el siglo XX. El mundo de lo privado, deja de ser un dominio exclusivo de ciertos sectores, para convertirse en un campo de batalla.

En la Argentina de los años 30 y 40’ los discursos que van a fortalecer y avalar muchas veces políticas respecto a lo familiar, fueron protagonizados por médicos. El lugar del “cuidado por el bien común” que caracterizó a la medicina en la primera mitad del siglo XX, permitió la introducción en la opinión pública de varias ideas que respondieron al recetario eugénico para pensar en términos poblacionales, la realidad local.

\section{Elegir es poblar. Clasificación, jerarquización y selección de pareja.}

La cuestión social de la herencia, fue para la eugenesia uno de los puntos fundamentales de su introducción en el discurso cientificista en Latinoamérica. Como estrategia discursiva en el entramado comunicacional, la información debía estar dirigida a la mujer, como principal protagonista de esta cuestión. De esta información dependería el desarrollo del hecho social y político de la maternidad, pensado desde una cuestión eugénica. Sin embargo, existieron una serie de mecanismos dispuestos para ejercer un control sobre la potencialidad de una pareja a la hora de transformar el compromiso humano en acuerdo legal. Para las décadas del 30’y 40’, el matrimonio constituía una institución clave en la historia social del país. Considerado como base fundamental de la familia- en el marco de un país donde la iglesia católica marcó su impronta en aspectos políticos y culturales- , la unión legal implicaba una serie de mecanismos desde donde se establecían parámetros antropométricos, que designaban la capacidad genésica de los futuros contrayentes. Aquellos a quienes estos parámetros biotipológicos ${ }^{4}$ no alcanzasen, se constituyeron en parte del peligro conspirativo que amenazaba el orden social ideado. 
Linares, L. Modelo para armar. Familia y roles de género a través del discurso eugénico en Argentina. 1934-1945 Derecho y Ciencias Sociales. Octubre 2018. № 19. (Las familias y el derecho de las familias a dos años de vigencia del Código Civil y Comercial) Pgs 4-21. ISNN 1852-2971. Instituto de Cultura Jurídica y Maestría en Sociología Jurídica. FCJ y S. UNLP

Ahora bien, la eugenesia como "ciencia del buen nacer", propuso establecer en la agenda política la preocupación por el carácter poblacional de la estructura social argentina. Es decir, legitimó discursivamente una serie de prácticas donde vida privada y pública dejaban de diferenciarse a los ojos de Estado, para medir distintas cuestiones a la hora de generar consensos sobre la formalidad de la unión familiar.

En la revista "Viva Cien Años" esto quedó plasmado en una serie de notas que utilizaban un discurso llano y sencillo para ejemplificar el "deber ser" de esas familias. Estas notas abundaban en los diversos números de la publicación refiriendo a la formación del matrimonio como un proceso, signado por el hábito constante de la selección. Este mecanismo, aparecía discursivamente, como natural a la condición humana, es decir, como parte del instinto propio de supervivencia. La selección de los candidatos adecuados, estaba íntimamente relacionada con la concepción del deseo de lo bueno, lo sano y lo fuerte. Estas tres dimensiones de la condición humana aparecen en VCA como parte del “deber ser" también -y fundamentalmente- en este proceso selectivo de pareja. Las notas llevan siempre títulos persuasivos, que interpelan a la lectora (o lector) y refieren a tres posibilidades: la consecución de un noviazgo consciente de la posibilidad de herencia fuerte, un noviazgo improvisado con posibilidades de educar en las ventajas del mejoramiento racial y un tercer tipo de noviazgo, producto de la ignorancia de los factores de herencia biológica y conducta social. Contra este tercer tipo de relación se establece una campaña para que las mujeres, ya sean las protagonistas del mismo, las madres de alguna de las partes o personas cercanas a los vinculados, ejerzan su deber de comunicar e interpelar a los novios acerca de la necesidad de realizar una visita a la asistente de higiene o al eugenista. Quienes no respondían a ese ideario conformaban una otredad construida científicamente.

Las operaciones discursivas para describir a cada una de las situaciones siempre involucran estrategias tendientes a generar empatía con alguno de los protagonistas, por parte del lector. Los títulos de los artículos son directos, breves, concisos y buscan interpelar a quien los lee. 
Linares, L. Modelo para armar. Familia y roles de género a través del discurso eugénico en Argentina. 1934-1945 Derecho y Ciencias Sociales. Octubre 2018. № 19. (Las familias y el derecho de las familias a dos años de vigencia del Código Civil y Comercial) Pgs 4-21. ISNN 1852-2971. Instituto de Cultura Jurídica y Maestría en Sociología Jurídica. FCJ y S. UNLP

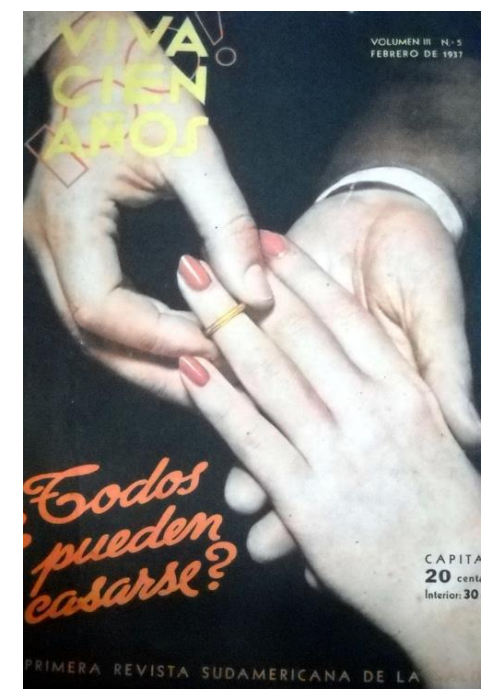

“¿Todos pueden casarse?. VCA: Vol. III, año 4, n5, febrero de 1937.

La propuesta de esta publicación referida al noviazgo, radicaba en una doble responsabilidad de la mujer y el hombre frente al contrato matrimonial futuro. Obviamente los deberes de ellos y ellas fueron muy distintos, así los miedos y las expectativas que podían generarse o esperarse antes de legitimar la forma familiar ante el Estado. En tanto categorías conceptuales, los eugenistas denominan a las relaciones prematrimoniales deseables como "noviazgo inteligente" como piedra fundacional del "matrimonio armónico", así respondieron a una serie de criterios establecidos según parámetros higienistas y eugenésicos. Las operaciones discursivas al respecto fueron variadas y siempre entrelazaban dos elementos clave para entender los mecanismos de penetración dentro del discurso social, de la eugenesia coercitiva disimulada: el carácter de consejo seguido por el aval técnico, brindado por la ciencia.

Desde cuestionarios, hasta pruebas caligráficas, se realizaban a la par de los exámenes médicos requeridos por el certificado. La elección matrimonial estaba fundada en fines específicos de reproducción consciente y educación eugenésica de las futuras generaciones. Así el "éxito social" de la unión matrimonial se traduce en el estado de obligación de los contrayentes para con la especie. La idea de una descendencia sana, fuerte que contribuya al engrandecimiento de la patria es vital para entender los términos y las secciones que utiliza la publicación a la hora de tratar el tema del matrimonio y la familia 5 .

Una vez iniciado el matrimonio, los concejos refieren a la responsabilidad de la

\footnotetext{
${ }^{5}$ Esta cuestión está presente tanto en el artículo de VEZZETTI (1985) y LINARES (2016).
} 
Linares, L. Modelo para armar. Familia y roles de género a través del discurso eugénico en Argentina. 1934-1945 Derecho y Ciencias Sociales. Octubre 2018. № 19. (Las familias y el derecho de las familias a dos años de vigencia del Código Civil y Comercial) Pgs 4-21. ISNN 1852-2971. Instituto de Cultura Jurídica y Maestría en Sociología Jurídica. FCJ y S. UNLP

mujer en la consolidación de esa unión. Los cuidados pueden clasificarse en tres ejes: del hogar, de los hijos y del marido. Respecto a este último, la principal advertencia que se le realiza a la mujer tiene que ver con la prevención de los excesos, producto de las pasiones. Tal vez, sobre este punto haya una clara coincidencia entre la noción de matrimonio eugénico con la noción clásica de matrimonio de la Iglesia católica. Las coincidencias son más que evidentes a la hora de abordar las sexualidades de los contrayentes y la responsabilidad de la mujer de retener a su marido a través del respeto al acuerdo conyugal, evitando el exceso. Muchos de los autores de las notas relacionadas al matrimonio y la sexualidad en el mismo, escriben en publicaciones académica y boletines, esas ideas radicalizadas. En ellas podemos notar una marcada relación entre Iglesia Católica y "mejoramiento racial" con enunciados mucho más duros que los que se reflejan en la publicación VCA. La vinculación entre la iglesia y la publicación se manifiesta, como ya dijimos por el abordaje de los temas y por quienes los abordan. Los miembros de las principales direcciones, como fue el caso de Annales de Biotipología, Eugenesia y Medicina Social (ABEMS) escribían en VCA de manera cotidiana. La ABEMS se constituyó en un organismo de consulta ante la planificación de políticas públicas y proyectos referidos a medicina social y problemáticas poblacionales (VALLEJO, 2010).

Fuera de la esfera oficial, se destaca la impronta que dejaron los médicos comprometidos en la causa eugénica, respecto a la divulgación mediante la revista VCA, donde fortalecieron su discurso y lugar de la medicina como monopolizadora del saber sobre los cuerpos. La estrategia discursiva fue distinta. El público a quien estaba dirigida la publicación del boletín de ABEMS, es radicalmente distinto. En este boletín, se escribía para colegas de distintos puntos del país y del continente, refiriéndose a los viajes y aprendizajes, así como los últimos estudios e informes, respecto a los saberes de la medicina preventiva y la eugenesia. El círculo de influencias cruzadas puede entrelazarse en esta publicación y en su reflejo en el proyecto de divulgación popular de saberes científicos e higiénicos.

Retomando la cuestión de la sexualidad dentro del matrimonio, respecto a los deberes de los cónyuges, el clima de la época legitima el discurso desde saberes normativos, como la medicina, pero también la religión, ya que es clara la influencia sobre la sanción de valores morales en las prácticas conyugales, emanadas de la Encíclica Casti Connubbi, llevada adelante por Pío XI en 1930 (MIRANDA,2011, 49). 


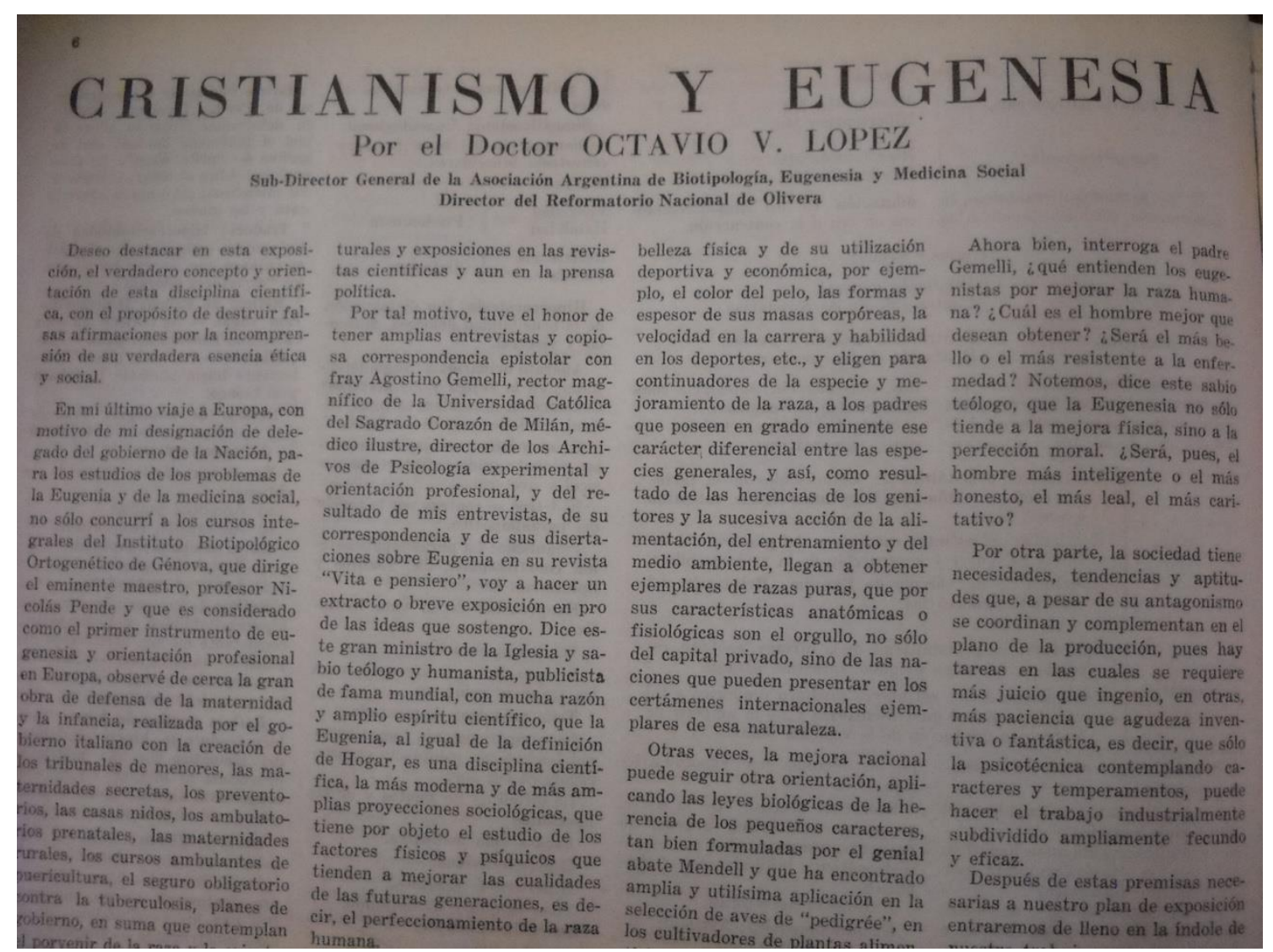

López, Octavio: Cristianismo y Eugenesia”. En Anales de Biotipología, Eugenesia y Medicina Social, Año III. No 9. Agosto de 1936. Pp. 6.

El mundo de los excesos, afectaba tanto a la mujer como al hombre. Según la mirada eugenésica, fue este último el que cae una y otra vez en la infidelidad como práctica que atenta y pone en peligro el cuerpo social, dada la proliferación de enfermedades venéreas que, mediante tales prácticas entran en el seno del hogar. La problematización de la situación recae en la mujer, como responsable del dominio de las pasiones de su esposo. Los celos, como momento de cuestionamiento parecen ser parte del ajuar recibido por la mujer a la hora de contraer matrimonio. Cuando se produce el caso contrario y es la mujer la que comete la infidelidad, la revista dirige las responsabilidades al cuerpo femenino que no resolvió los avatares de la "coquetería excesiva" o alguna conducta patológica de la mujer.

\section{La mujer ideada por la eugenesia: El deber ser y los cuidados para con el modelo} de familia.

Volviendo a los cuidados dispuestos en la publicación VCA, respecto al hogar, están relacionados a las prácticas modernas y las formas establecidas para resolver los problemas propios del ingreso de nuevos mecanismos de consumo en los hogares. Como operaciones 
Linares, L. Modelo para armar. Familia y roles de género a través del discurso eugénico en Argentina. 1934-1945 Derecho y Ciencias Sociales. Octubre 2018. № 19. (Las familias y el derecho de las familias a dos años de vigencia del Código Civil y Comercial) Pgs 4-21. ISNN 1852-2971. Instituto de Cultura Jurídica y Maestría en Sociología Jurídica. FCJ y S. UNLP

discursivas sobre este punto, fueron varias. La que más llama la atención es la de las autoevaluaciones de la mujer sobre el cuidado del hogar. Una serie, en principio, de consejos sobre actividades y problemas a resolver en la vida diaria dentro del hogar y luego una evaluación con situaciones hipotéticas y preguntas. Luego de cotejar, en el número siguiente, las respuestas dadas con las soluciones propuestas por los profesionales, la mujer puede concluir acerca del grado de manejo de los cuidados del hogar que posee.

Ningún binomio fue más constituyente para la eugenesia latina, al hablar de los modelos de familia que la relación entre la mujer y la maternidad. La cuestión de género y de los cuerpos femeninos se entrelazaban con el diseño de políticas sociales y la corriente eugenésica vigentes en el país. Siendo que: "En la Argentina, las mujeres vivieron la experiencia de ser la periferia de la periferia" (PITA-INI, y GIL LOZANO, 2000, 12.). Las políticas sobre los cuerpos femeninos se ejercían a través de varios mecanismos. El patrón 'ideal' de comportamiento de las mujeres imponía tareas vinculadas a su rol de madre. La función del cuerpo femenino como transmisor de los ideales de la nación, proponía el cuidado de la salud femenina como una cuestión que estaba íntimamente ligado a ello.

La mujer era parte activa de las fuerzas productivas y enfrentaba un desafío tanto para ella, como para la clase dirigente que tenía que redefinir el lugar de la mujer obrera. Para ellas, el cuestionamiento al salir del hogar para ocupar un lugar en el mundo del trabajo y exponerse a las vicisitudes del mundo moderno, siendo parte de ese mundo en condiciones desiguales respecto al varón. La descalificación social, de la cual eran víctimas estas mujeres respondía a las construcciones erigidas sobre cuerpos ajenos. Este desafío que afrontaban ellas, respondía también a combinar, en el plano de lo real, la función de trabajadora con la de madre, además de batallar con el imaginario social alrededor de la mujer y con las condiciones materiales de ese trabajo: “... la mujer obrera era una especie de híbrido degenerado y potencialmente degenerador. Al integrarse en el trabajo industrial, al procurarse para ella y su familia un salario, la mujer obrera se convertía en un elemento disgregador..." (LOBATO, 2000, 100).

La mujer pensada tanto organismo reproductor y agente educador del ideario de la nación contrariaba con la realidad de muchas mujeres obreras. Esta realidad generaba debates y acuerdos entre diversos sectores políticos. Socialistas, católicos, radicales y conservadores exponían las desventajas de esta situación. El discurso católico sobre la cuestión de género no se hizo esperar y a partir de las distintas publicaciones llamaban a construir la feminidad articulando “...el control de las familias con las conveniencias de la patria." (ACHA, 2000, 
Linares, L. Modelo para armar. Familia y roles de género a través del discurso eugénico en Argentina. 1934-1945 Derecho y Ciencias Sociales. Octubre 2018. № 19. (Las familias y el derecho de las familias a dos años de vigencia del Código Civil y Comercial) Pgs 4-21. ISNN 1852-2971. Instituto de Cultura Jurídica y Maestría en Sociología Jurídica. FCJ y S. UNLP

P. 162.). La idea de contribución a la patria se funde con la idea de contribución a la raza. Desde finales de siglo XIX en América Latina comienzan a difundirse las ideas de la conservación de la "raza" frente a los avatares propios del proceso de inmigración masiva.

Como vimos, durante la primera mitad del siglo XX, se extendieron dos corrientes de pensamiento que referían a la cuestión del control sobre los cuerpos. La eugenesia y la biotipología. Ambas escuelas respondían al nuevo contexto de una Argentina que se inserta de lleno en el sistema capitalista que necesitaba reformular respuestas para la nueva realidad. Entre esas preocupaciones y como vimos anteriormente la cuestión de la mujer y del niño como 'mejoradores' de la raza, era central. La eugenesia y la Iglesia Católica compartían preocupaciones referidas a la mujer ${ }^{6}$. Fichas biotipológicas, controles y restricciones legales hacían al control eugenésico de la población. Para la eugenesia, la presencia de la madre en el hogar implicaba características positivas sobre su descendencia, fuera de los valores morales que puede transmitir la madre, su presencia con sus hijos en el hogar estimulaba características como la inteligencia de los niños ${ }^{7}$.

A pesar de los postulados de estos sectores, la realidad indicaba que la inserción de las mujeres en el ámbito del trabajo crecía. Tanto es así que para 1924 se agregaron distintos incisos en la ley de 1907 presentada por Alfredo Palacios, que regulaba el trabajo femenino. La agenda política y legislativa intentaba dar respuesta a la realidad que postulaba a la mujer como parte activa del mundo del trabajo. Sin embargo el reconocimiento pleno de los derechos laborales será asimétrico y anacrónico- respecto al de los varones- y sus cuerpos fuertemente regulados.

Entre 1920 y 1940, se consolida en las agendas políticas la necesidad de plantear la cuestión de la maternidad como asunto "público" y de incumbencia del Estado ${ }^{8}$, siendo que para las ciencias médicas que legitimaban el discurso político referido a la maternidad, la figura del "cuerpo femenino sólo aparecía adquiriendo sentido a través de la procreación, la crianza de los niños, la maternidad...Todas otras posibles facetas de la vida sexual y social de las mujeres quedaban oscurecidas por la maternidad” (NARI, 2004,175). Siendo así, la

\footnotetext{
6 Adscribiendo a los postulados de O'LERY que afirma que : “ En el caso argentino, los presupuestos eugenésicos estuvieron presentes en el planeamiento sanitario, educativo...y en buena medida delineados a partir de una fuerte impronta de los preceptos de la Iglesia Católica, que lejos de mantenerse al margen intento ser una voz más en el debate..." en su artículo: Aportes acerca de la relación Iglesia-eugenesia en Argentina" en VALLEJO y MIRANDA (comp.) (2007).

${ }^{7}$ Así lo explica O’LERY cuando analiza el rol que tenía la mujer para la eugenesia en Argentina. Op. Cit. Pp. 373.

${ }^{8}$ Como bien se explica en Nari Marcela:Op. Cit.. Buenos Aires: Biblos, 2004.
} 
Linares, L. Modelo para armar. Familia y roles de género a través del discurso eugénico en Argentina. 1934-1945 Derecho y Ciencias Sociales. Octubre 2018. № 19. (Las familias y el derecho de las familias a dos años de vigencia del Código Civil y Comercial) Pgs 4-21. ISNN 1852-2971. Instituto de Cultura Jurídica y Maestría en Sociología Jurídica. FCJ y S. UNLP

cuestión de la madre y el niño, atraviesa todos los abordajes respecto a la mujer que realiza la publicación. En la niñez, reside la posibilidad de cambio eugénico del cuerpo social todo. La madre, se transforma en la reserva moral y ambiental de la preocupación por la "raza" en el país.

Médicos y profesionales de la salud utilizaban publicaciones como Viva Cien Años, Hijo Mio! y Nuestros Hijos para legitimar ese lugar de la mujer y cómo debía darse dentro del imaginario eugenésico. Los doctores, Renato Kehl, Alberto Seguín, Mario Alzúa, Profesor Jaime Beltrán, reconocidos profesionales en el campo de la eugenesia en América Latina escribieron frecuentemente en las revistas, principalmente en Viva Cien Años. En las revistas Hijo Mío! y Nuestros Hijos, la imagen de la maternidad y la mujer madre estaba siempre vinculada no solo a la idea de deber sino que se establecía una clara relación con la idea de realización, plenitud y felicidad.

La revista Hijo Mío radicaliza algunas cuestiones que se dejan ver en VCA, referidas a la mujer y sus deberes dentro de la familia y como responsable de la educación de cuerpo y espíritu del niño. La figura masculina está en un segundo plano, haciendo hincapié en la importancia de la selección a la hora de la herencia de caracteres. El "leitmotiv" de la revista parte de esa base: “El niño es el padre del hombre, mejorémoslo!” 
Linares, L. Modelo para armar. Familia y roles de género a través del discurso eugénico en Argentina. 1934-1945 Derecho y Ciencias Sociales. Octubre 2018. № 19. (Las familias y el derecho de las familias a dos años de vigencia del Código Civil y Comercial) Pgs 4-21. ISNN 1852-2971. Instituto de Cultura Jurídica y Maestría en Sociología Jurídica. FCJ y S. UNLP

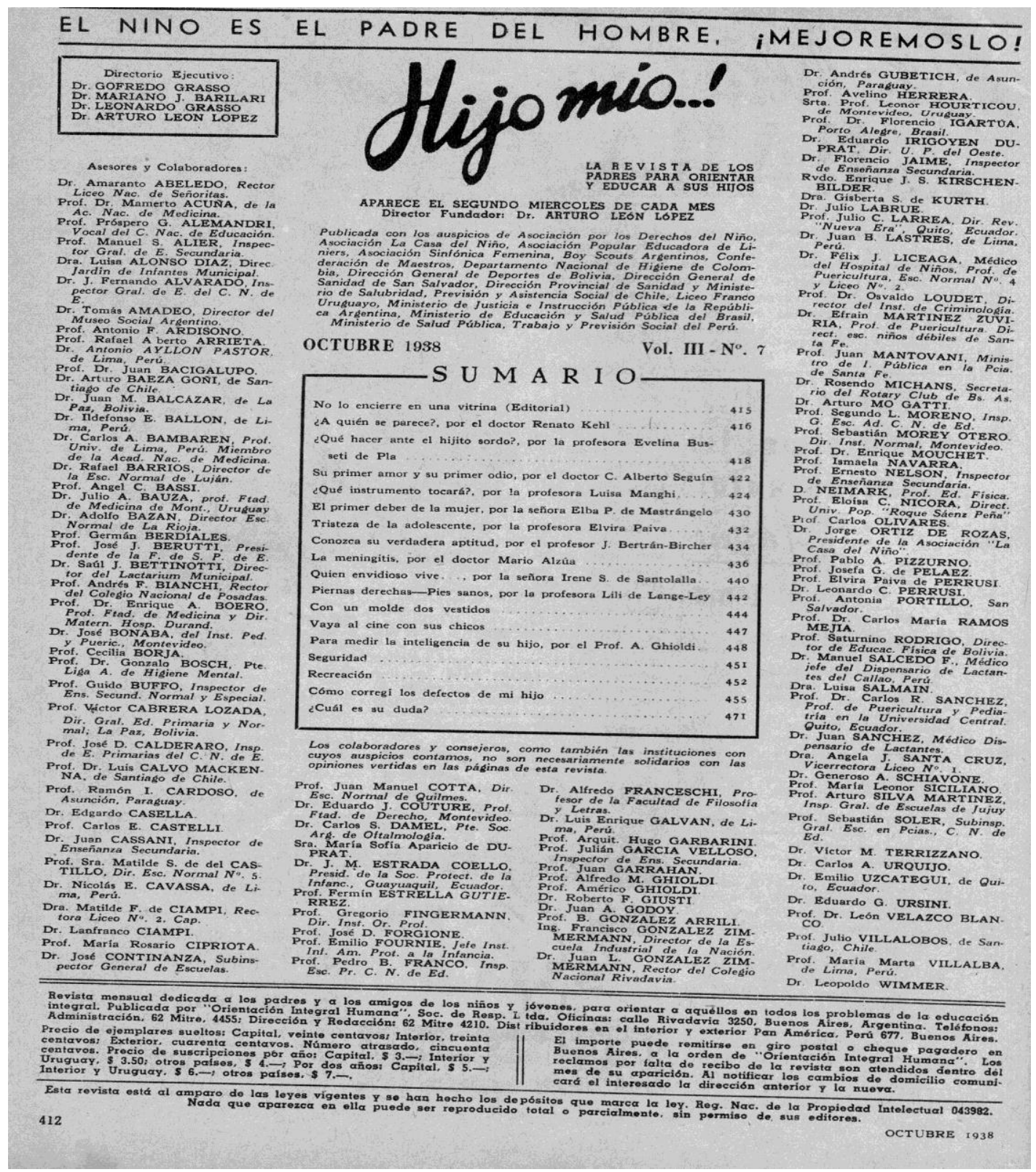

Revista “Hijo Mío!” Volumen II. Octubre de 1938. Índice.

Las largas fundamentaciones, los diminutivos, las formas de interpelación a los lectores como responsables de la crianza en valores y la preocupación por la salud de sus hijos a partir de una construcción social del lugar de la mujer en un contexto de cambio como se dio en la década del treinta, son señas de esta revista. Como sujeto lector y protagonista de la mayoría de las notas de la publicación, ya que aquellas que no refieren a bebés, niños refieren a las adolescentes, haciendo hincapié en su rol de futuras madres. Veamos algunos ejemplos: 
Linares, L. Modelo para armar. Familia y roles de género a través del discurso eugénico en Argentina. 1934-1945 Derecho y Ciencias Sociales. Octubre 2018. № 19. (Las familias y el derecho de las familias a dos años de vigencia del Código Civil y Comercial) Pgs 4-21. ISNN 1852-2971. Instituto de Cultura Jurídica y Maestría en Sociología Jurídica. FCJ y S. UNLP

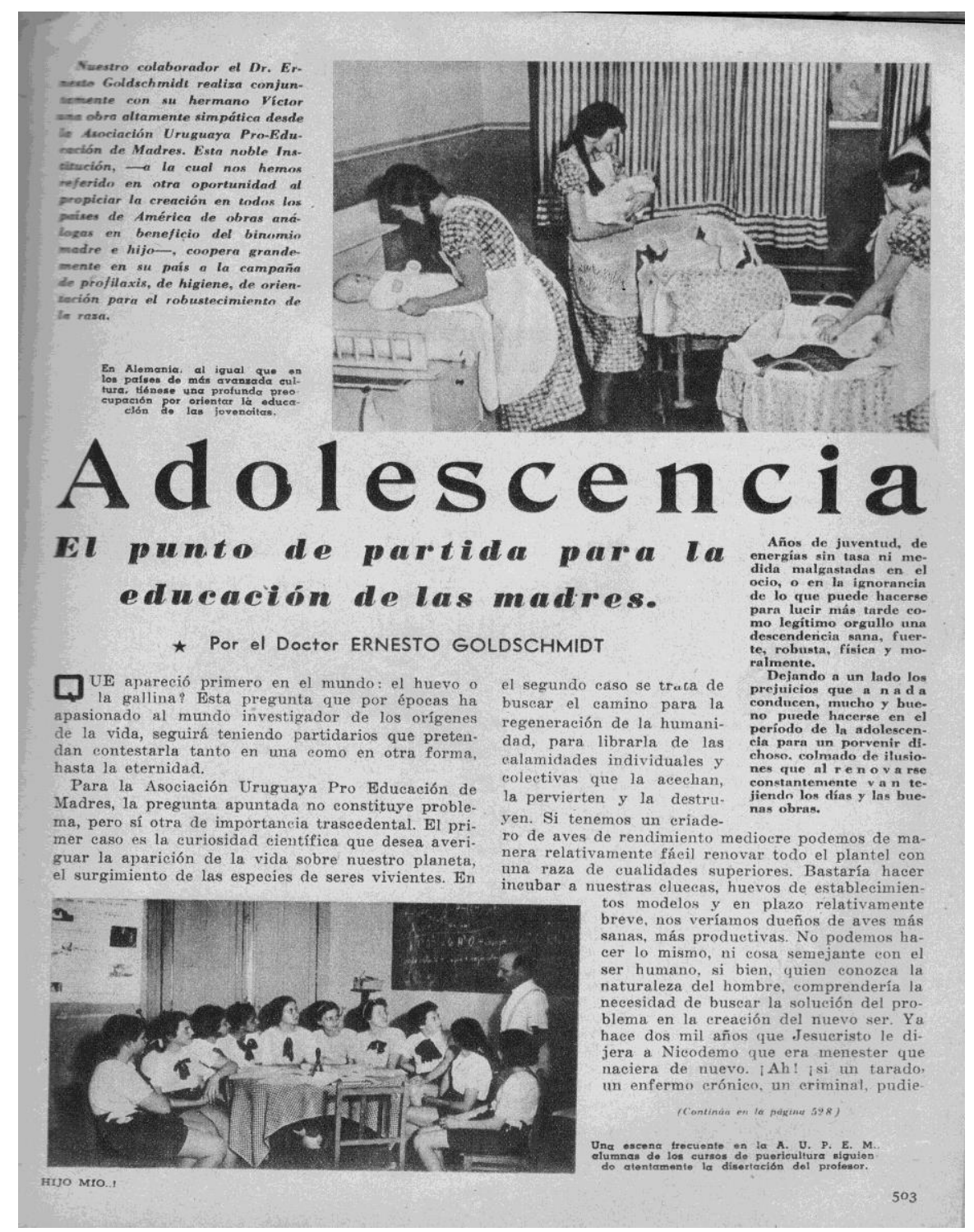

Revista “Hijo Mío!” Octubre de 1938. pp. 430 
Linares, L. Modelo para armar. Familia y roles de género a través del discurso eugénico en Argentina. 1934-1945 Derecho y Ciencias Sociales. Octubre 2018. № 19. (Las familias y el derecho de las familias a dos años de vigencia del Código Civil y Comercial) Pgs 4-21. ISNN 1852-2971. Instituto de Cultura Jurídica y Maestría en Sociología Jurídica. FCJ y S. UNLP

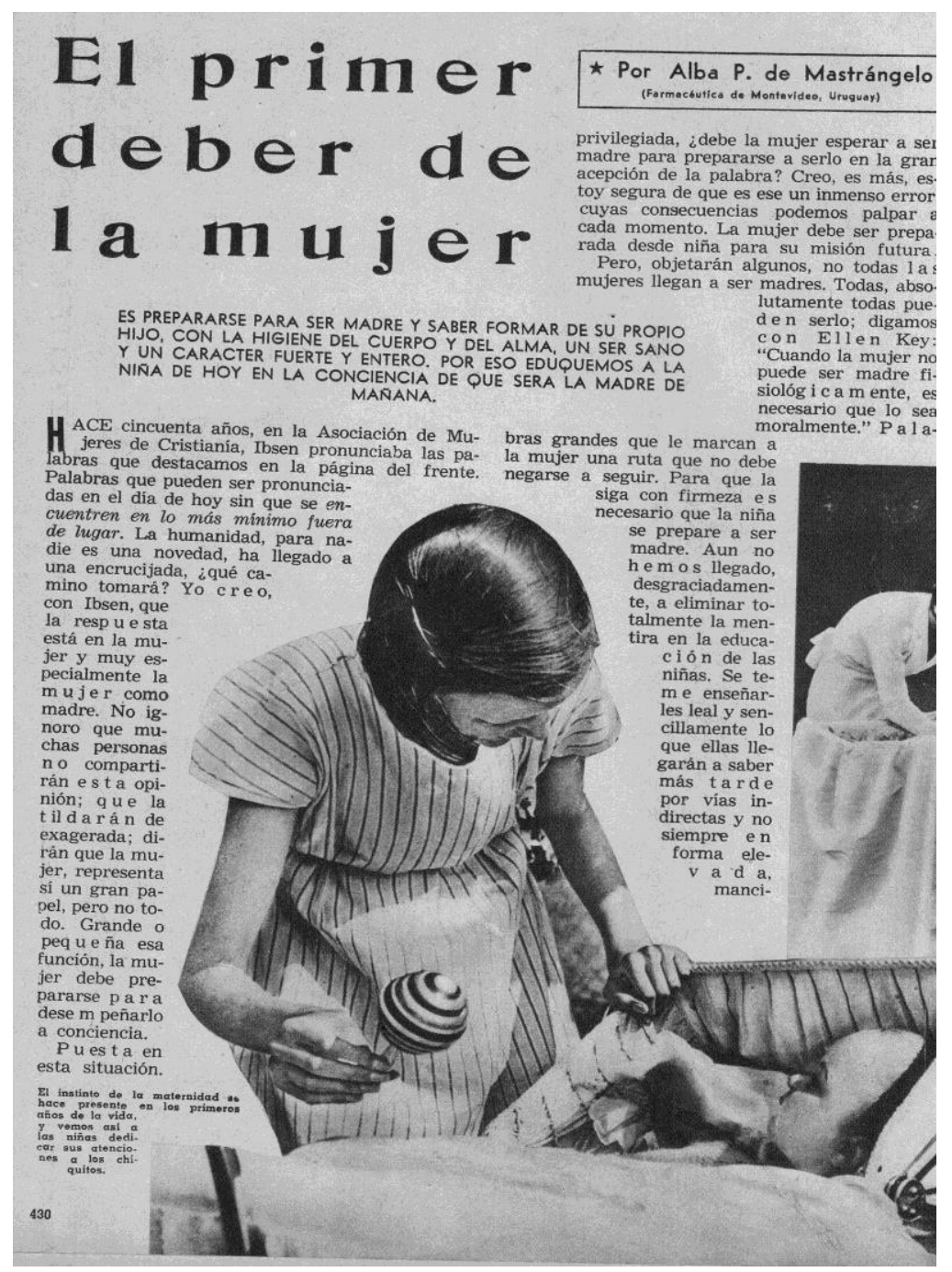

Revista “Hijo Mío!”. Volumen III. No 7, Noviembre de 1938. pp. 503.

La cuestión de la herencia se vuelve centro de la eugenesia en Argentina, acompañando el clima general en América Latina. Las secciones de las publicaciones aconsejan acerca del mejoramiento de sus hijos y de los problemas con los que no debería encontrarse el ciudadano higiénico. Espacios como: "Para medir la inteligencia de sus hijos", "Como corregir los defectos de mi hijo", "Pequeñas causas...grandes defectos" o "Cuál es su duda" refuerzan lo antedicho, ya que con un lenguaje coloquial y haciendo mención a elementos que refieren a la cotidianeidad de la relación médico- paciente, la revista Hijo Mío hace uso de conceptos propios de la divulgación de la teoría de la eugenesia, en su variable latina. Con esta revista queda de manifiesto la función social que tenía este tipo de publicaciones a la hora de llegar a los hogares de los sectores medios de la población. 
Linares, L. Modelo para armar. Familia y roles de género a través del discurso eugénico en Argentina. 1934-1945 Derecho y Ciencias Sociales. Octubre 2018. № 19. (Las familias y el derecho de las familias a dos años de vigencia del Código Civil y Comercial) Pgs 4-21. ISNN 1852-2971. Instituto de Cultura Jurídica y Maestría en Sociología Jurídica. FCJ y S. UNLP

Dirigida a madres “...amorosas y prudentes que desean que su hijo sea feliz...” esta publicación de divulgación se presentaba como una respuesta a los avatares de asumir la maternidad y responsabilidad por educar un hijo, no como individuo sino como ser colectivo que responde un modelo de infancia que empieza a mostrar nuevas sensibilidades.

Estas madres pensadas por el ideario eugénico, debían educan las generaciones futuras en preocupaciones tales como la salud de los cuerpos y su relación para con el cuerpo social; una raza fuerte que represente al biotipo argentino; la herencia genética y la importancia de los procesos de selección previos a la llegada del niño. La cuestión de la herencia se vuelve, para los eugenistas criollos, el canal mediante el cual llegar al mejoramiento de la raza. El ciudadano eugénico que se pensó, tiene el deber de analizar la posibilidad de matrimonio como parte de la cuestión social de la herencia.

\section{A modo de cierre}

Si el ideario católico plantea que la familia es la base de la sociedad, podemos afirmar que la eugenesia propone que la mujer es el pilar fundamental de la familia, para la primera mitad del siglo XX. Así, tanto los modelos de familias como las definiciones de género se transforman en íntima relación con las sociedades y las coordenadas socio históricas. Como un entramado delicado de relaciones, la familia en clave eugénica y perspectiva histórica se plantea como una institución capaz de ser mejorada por el adoctrinamiento de sus participantes. Sin embargo, dentro del modelo para armar que propuso la eugenesia en esta coordenada espacio temporal, las responsabilidades se establecen siguiendo deberes de género. Fueron las mujeres el centro de las prácticas de difusión y divulgación de la teoría eugenésica en el seno de la vida privada de las personas. En ellas recaían las decisiones respecto al futuro "biotipo" argentino.

Ahora bien, que ocurría con aquellos cuerpos femeninos que no respondía a esta idea de mujer-madre-difusora. Estos cuerpos que ponían en peligro al cuerpo social se constituían en la otredad. Ese otro al cual temer tanto agente capaz de demoler las construcciones culturales erigidas por la Iglesia católica y avaladas por un discurso científico que buscaba el "bien común" de la sociedad. Las decisiones políticas sobre los cuerpos femeninos y el cuerpo social todo, buscan construir en ese "otro" un peligro mientras legitiman prácticas que 
Linares, L. Modelo para armar. Familia y roles de género a través del discurso eugénico en Argentina. 1934-1945 Derecho y Ciencias Sociales. Octubre 2018. № 19. (Las familias y el derecho de las familias a dos años de vigencia del Código Civil y Comercial) Pgs 4-21. ISNN 1852-2971. Instituto de Cultura Jurídica y Maestría en Sociología Jurídica. FCJ y S. UNLP

establecen una manera de vivir y ejercer sobre la vida de las personas, fusionando por momentos, poder y saber.

Así los discursos sobre los cuerpos femeninos cambiaron, en función de las realidades socio históricas, a partir de discursos que logran consenso en diferentes sectores, plantean agendas políticas y siempre construyeron poder sobre los cuerpos ajenos. Sin embargo, la historia de los modelos de familia, se erige en función de las luchas y las realidades cotidianas que se imponen a estas formas del "deber ser" que luego se traducen en nuevos embates que dan como resultado modificaciones y nuevas prácticas en pos del reconocimiento de derechos humanos vitales para la vida en sociedades democráticas.

Este artículo intento vincular un modelo de familia, en una coyuntura cambiante en Argentina, a partir de las construcciones discursivas de medios de comunicaciones especializados pero populares (como lo fueron Viva Cien Años, Hijo Mío! y Nuestros Hijos), que utilizaban las formas del saber científico para avalar un modelo de familia determinado también por modelos económicos, culturales y religiosos. Con la construcción de este objeto de estudio, nos proponemos establecer el grado de influencia que pueden tener los medios de comunicación en la legitimidad de las prácticas inherentes a la aceptación, reivindicación o crisis de determinados modelos de familia.

\section{Bibliografía}

Acha, O. y Halperín P. (comp.) (2000). Cuerpos, géneros e identidades. Buenos Aires. Del signo.

Aries, P. (1966). El niño y la vida familiar en al antiguo régimen. Madrid: Taurus.

Caponi, S., Vasquez Valencia M. F. y Verdi M. (comp.) (2016). Vigiar e medicar: Estratégias de medicalizacao da infancia. Sao Paulo: LiberArt.

Gil Lozano, F. y Pita V. (Dir.)(2000). Historia de las mujeres en la Argentina. Siglo XX, Buenos Aires, Taurus.

Linares, L. (2014). Delineando los cuerpos. Construcciones discursivas en torno a la mujer a través de la propaganda eugénica en Argentina. El caso de la publicación Viva Cien Años. 1935/1947.(Tesis de Maestría en Historia) Universidad Nacional de Mar del Plata, Facultad de Humanidades, Departamento de Historia. Julio 2014. 
Linares, L. Modelo para armar. Familia y roles de género a través del discurso eugénico en Argentina. 1934-1945 Derecho y Ciencias Sociales. Octubre 2018. № 19. (Las familias y el derecho de las familias a dos años de vigencia del Código Civil y Comercial) Pgs 4-21. ISNN 1852-2971. Instituto de Cultura Jurídica y Maestría en Sociología Jurídica. FCJ y S. UNLP

Linares, L (2016). Matrimonios y algo más. Discurso eugénico en torno a la selección de pareja. El caso de la revista Viva Cien Años, 1935/1937”. Avances del Cesor, V. XIII, No 14, Primer semestre 2016, pp. 89-109

Lobato, M. (editora) (1996): Política, médicos y enfermedades. Lecturas de historia de la salud en la Argentina. Mar del Plata: Biblos.

Lobato, M. (2000). Lenguaje laboral y género en el trabajo industrial. Primera mitad del siglo XX. En Gil Lozano, F. y Pita V. (Dir.)(2000). Historia de las mujeres en la Argentina. Siglo XX, Buenos Aires, Taurus.

Lovera, S. (2009). Comunicación y género. El reto de este siglo denominado de la Sociedad de la Información. Know How y ciudadanía: potencial de las nuevas tecnologías para la comunicación y la acción de las mujeres en el siglo XXI. México: UNAMPUEG, UNIFEM, 219-226.

Miranda, M. (2011). Controlar lo incontrolable. Una historia de la sexualidad en la Argentina. Buenos Aires: Biblos Miranda, M. y Vallejo G. (dir.) (2012): Una historia de la Eugenesia. Argentina y las redes biopolíticas internacionales. 1912-1945. Buenos Aires: Biblos.

Moreno, J. L. (Comp.),(2000). La política social antes de la política social. Buenos Aires: Prometeo libros.

Nari, M.(1996). Las prácticas anticonceptivas, la disminución de la natalidad y el debate médico. 1890-1940. En: Lobato, M. (editora). Política, médicos y enfermedades. Lecturas de historia de la salud en la Argentina. Mar del Plata: Biblos.

Nari, M. (2004). Políticas de maternidad y maternalismo político. Buenos Aires: Biblos.

O’lary, M. (2006) Aportes acerca de la relación Iglesia-eugenesia en Argentina. En Vallejo, G. y Miranda M. (comp. ). Políticas del cuerpo. Estrategias modernas de normalización del individuo y la sociedad. Buenos Aires: Siglo XXI, pp. 365, 366.

Parsons, T. y Bales, R. (1955) Family, Socialization and Interaction Process. New York: The Free Press.

Pérez I. y Ribeiro Dos Santos M. (Comp.) (2017). Gênero e consumo no espaço doméstico. Representações durante o século XX na Argentina e no Brasil. Curitiba: ABEU.

Segalen, M. (2013). Sociología de la familia. Mar del Plata: EUDEM.

Suriano J. y Lvovich D. (2005). Las políticas sociales en perspectiva histórica. Argentina, 1870- 1952. Buenos Aires: Prometeo Libros. 
Linares, L. Modelo para armar. Familia y roles de género a través del discurso eugénico en Argentina. 1934-1945 Derecho y Ciencias Sociales. Octubre 2018. № 19. (Las familias y el derecho de las familias a dos años de vigencia del Código Civil y Comercial) Pgs 4-21. ISNN 1852-2971. Instituto de Cultura Jurídica y Maestría en Sociología Jurídica. FCJ y S. UNLP

Vezzetti, H (1985). Viva Cien Años: Algunas consideraciones sobre la familia y matrimonio en la Argentina en: Punto de Vista. Año IX, nº 27, Agosto de 1985.

Zimmermann, E. y Ben Plotkin, M.(2012a). Las prácticas del Estado. Política, sociedad y elites estatales en la Argentina del siglo XX. Buenos Aires: EDHASA.

Zimmermann, E. y Ben Plotkin, M.(2012a) (2012b) Los saberes del Estado. Buenos Aires: EDHASA. 